\title{
Toward an attention-based diagnostic tool for patients with locked-in syndrome
}

Citation for published version (APA):

Lesenfants, D., Habbal, D., Chatelle, C., Soddu, A., Laureys, S., \& Noirhomme, Q. (2018). Toward an attention-based diagnostic tool for patients with locked-in syndrome. Clinical Eeg and Neuroscience, 49(2), 122-135. https://doi.org/10.1177/1550059416674842

Document status and date:

Published: 01/03/2018

DOI:

10.1177/1550059416674842

Document Version:

Accepted author manuscript (Peer reviewed / editorial board version)

\section{Please check the document version of this publication:}

- A submitted manuscript is the version of the article upon submission and before peer-review. There can be important differences between the submitted version and the official published version of record.

People interested in the research are advised to contact the author for the final version of the publication, or visit the DOI to the publisher's website.

- The final author version and the galley proof are versions of the publication after peer review.

- The final published version features the final layout of the paper including the volume, issue and page numbers.

Link to publication

\footnotetext{
General rights rights.

- You may freely distribute the URL identifying the publication in the public portal. please follow below link for the End User Agreement:

www.umlib.nl/taverne-license

Take down policy

If you believe that this document breaches copyright please contact us at:

repository@maastrichtuniversity.nl

providing details and we will investigate your claim.
}

Copyright and moral rights for the publications made accessible in the public portal are retained by the authors and/or other copyright owners and it is a condition of accessing publications that users recognise and abide by the legal requirements associated with these

- Users may download and print one copy of any publication from the public portal for the purpose of private study or research.

- You may not further distribute the material or use it for any profit-making activity or commercial gain

If the publication is distributed under the terms of Article $25 \mathrm{fa}$ of the Dutch Copyright Act, indicated by the "Taverne" license above, 


\title{
Toward an Attention-Based Diagnostic Tool for Patients With Locked-in Syndrome
}

\author{
Damien Lesenfants ${ }^{1,2,3}$, Dina Habbal $^{1}$, Camille Chatelle ${ }^{1,4}$, Andrea Soddu ${ }^{1,5}$, Steven Laureys ${ }^{1}$, \\ and Quentin Noirhomme ${ }^{1,6,7}$
}

\begin{abstract}
Electroencephalography (EEG) has been proposed as a supplemental tool for reducing clinical misdiagnosis in severely brain-injured populations helping to distinguish conscious from unconscious patients. We studied the use of spectral entropy as a measure of focal attention in order to develop a motor-independent, portable, and objective diagnostic tool for patients with locked-in syndrome (LIS), answering the issues of accuracy and training requirement. Data from 20 healthy volunteers, 6 LIS patients, and 10 patients with a vegetative state/unresponsive wakefulness syndrome (VS/UWS) were included. Spectral entropy was computed during a gaze-independent 2-class (attention vs rest) paradigm, and compared with EEG rhythms (delta, theta, alpha, and beta) classification. Spectral entropy classification during the attention-rest paradigm showed $93 \%$ and $91 \%$ accuracy in healthy volunteers and LIS patients respectively. VS/UWS patients were at chance level. EEG rhythms classification reached a lower accuracy than spectral entropy. Resting-state EEG spectral entropy could not distinguish individual VS/UWS patients from LIS patients. The present study provides evidence that an EEG-based measure of attention could detect command-following in patients with severe motor disabilities. The entropy system could detect a response to command in all healthy subjects and LIS patients, while none of the VS/UWS patients showed a response to command using this system.
\end{abstract}

\section{Keywords}

locked-in syndrome, diagnostic tool, response to command, focal attention, entropy

Received March 18, 2016; revised September 9, 2016; accepted September 19, 2016.

\section{Introduction}

Locked-in syndrome (LIS) is characterized by severe motor disabilities, including aphonia or severe hypophonia, quadriplegia or quadriparesis, together with preserved cognitive abilities allowing for primary and elementary communication code using vertical eye movements or blinking. ${ }^{1}$ According to Bauer et $a l,{ }^{2}$ LIS can be subdivided based on the severity of motor impairments: classical LIS is characterized by total immobility except for vertical eye movements or blinking; incomplete LIS still shows remnants of voluntary motion; and complete/total LIS consists of complete immobility including all eye movements. The two most common causes of LIS are a bilateral ventral pontine lesion following a vascular pathology or a traumatic brain injury, and amyotrophic lateral sclerosis, a motor-neuron degenerative disease that can potentially lead to a complete LIS. The rarity of locked-in syndrome due to acute ventral lesion often results in the diagnosis being delayed or even missed, and in the underestimation of preserved cognitive abilities when these patients are encountered in clinic. ${ }^{3}$ Difficulties in diagnosis could also be explained by the difficulty of recognizing unambiguous signs of consciousness in severely brain injured patients, by the apparent similarity with the unresponsive wakefulness syndrome/vegetative state (VS/UWS; ie, eyes opening and motor immobility without signs of awareness $)^{4}$ but also by a possible fluctuation of the arousal level in the acute stage. ${ }^{5}$ For these reasons, a high rate of misdiagnosis is very likely to happen, especially in complete LIS. ${ }^{3,6,7}$ However, early detection of signs of consciousness in LIS is crucial in terms of medical care, rehabilitation and quality of life. ${ }^{3}$

\footnotetext{
${ }^{1}$ Coma Science Group, GIGA-Research, CHU University Hospital of Liege, Liege, Belgium

${ }^{2}$ School of Engineering and Institute for Brain Science, Brown University, Providence, RI, USA

${ }^{3}$ Center for Neurorestoration and Neurotechnology, Rehabilitation R\&D Service, Department of VA Medical Center, Providence, RI, USA

${ }^{4}$ Department of Physical Medicine and Rehabilitation, Spaulding Rehabilitation Hospital, Harvard Medical School, Boston, MA, USA

${ }^{5}$ Brain and Mind Institute, Physics and Astronomy Department, University of Western Ontario, London, Ontario, Canada

${ }^{6}$ Brain Innovation B.V., Maastricht, the Netherlands

${ }^{7}$ Faculty of Psychology and Neuroscience, Maastricht University, Maastricht, the Netherlands
} 
In this context, motor-independent paraclinical tools have been proposed to facilitate the detection of signs of consciousness, such as command-following, in the acute stage and improve quality of life in the chronic stage using computer-based communication $^{8-11}$ (for a review, see Naci et al, ${ }^{12}$ Chatelle et al, ${ }^{13}$ and Chaudhary et al ${ }^{14}$ ). In particular, electroencephalography (EEG)-based brain-computer interfaces (BCIs) constitute an interesting approach as they allow direct recording of the brain activity without the intervention of behavioral motor responses or invasive surgery. ${ }^{15}$ The successful use of BCIs by large population of healthy users has been reported in several studies. ${ }^{16-20}$ Alongside, many studies have shown that these systems are feasible and practical for patient groups, ${ }^{9,21}$ However, when studying LIS and complete LIS, current EEG-based BCIs suffer from limited accuracy, ${ }^{11,22-24}$ task complexity, ${ }^{23}$ motor dependency, ${ }^{9,25}$ and/or long user training. ${ }^{9}$ Task-related variation of focal attention could be used in such attention-driven paradigm to help probing command-following. The ability to sustain attention in a task for a period of time ${ }^{26,27}$ can be measured with EEG without the intervention of behavioral responses. ${ }^{28}$ Evoked potential response under different attentional levels ${ }^{29-31}$ and power spectral density distribution or the energy changes of specific EEG rhythms ${ }^{32}$ have been proposed to evaluate the level of attention but have never been combined with an attention-based paradigm in brain-injured patients. Entropy originates from a measure of information called Shannon entropy ${ }^{33}$ and is a measure of signal regularity or predictability; usually, a high value corresponds to increased irregularity or unpredictability (eg, uniform distribution of the power spectrum), while a low value corresponds to high regularity (eg, concentration of the activity in a single band). Approximate, ${ }^{34}$ permutation, ${ }^{35}$ and spectral $^{36,37}$ entropy measures have been applied to EEG. Entropy values have been found to decrease consistently from wake to sleep with the lowest value occurring during deep sleep. ${ }^{38,39}$ Entropy has been shown to correlate with anesthetic depth. ${ }^{35,37,40-42}$ It has also been applied to detect epileptic seizures ${ }^{43}$ and to evaluate the level of consciousness in postcomatose patients ${ }^{44-48}$ but has never been proposed as a measure of attention or vigilance during a task. The interested reader will find a more detailed explanation of the link between entropy values and EEG signals in Viertio-Oja et al. ${ }^{37}$

The aim of the present work was to propose task-related modification of attention, evaluated using spectral entropy (SpE), as a motor-independent tool to detect response to command in severely brain-injured patients. We hypothesized that an increase of attention related to the task may be observed in conscious patients (LIS) but not in unconscious patients (VS/UWS).

\section{Materials and Methods}

We analyzed data acquired in our previous study on covert steady-state visually evoked potentials (SSVEP)-based BCI in healthy volunteers and patients with LIS. ${ }^{11}$ In this study, the participants had to concentrate on yellow or red interleaved patterns flashing at different frequencies. A classifier was trained on the spectral features to distinguish yellow from red trials. An accuracy higher than chance level was seen as proof of the ability of the participant to follow a command and was obtained in 20 out of 24 healthy volunteers and 2 out of the 6 LIS patients. In the present study, we randomly selected 20 healthy volunteers out of the 24 , and we added new data acquired in patients with VS/UWS to the initial cohort. We then analyzed the difference between rest trials and attention trials (collapsing red and yellow trials), hereinafter named passive and active trials, respectively.

\section{Participants}

Twenty healthy volunteers ( 6 men; age $28 \pm 8$ years), 6 LIS patients ( 2 classical and 4 incomplete; 4 men; age $49 \pm 20$ years; 5 with cerebrovascular accident and 1 trauma; interval since insult $8 \pm 5$ years; see Table 1 for demographic and clinical data of patients with LIS) and 10 patients with VS/UWS (6 men; age $43 \pm 15$ years; interval since insult $3 \pm 2$ years; see Table 2 for demographic and clinical data of VS/UWS patients) participated in this study. None had prior experience with EEG-based BCI studies. The study was approved by the ethical committee of the University Hospital of Liege and all participants, or their legal representative, provided informed consent. No participants were excluded from the study, and all chose to participate. The Coma Recovery Scale-Revised (CRS-R) was used to define the clinical diagnosis of patients with VS/UWS. The CRS-R is currently the most sensitive tool for disentangling conscious from unconscious responses following a brain injury. ${ }^{49,50}$ Trained neuropsychologists conducted the CRS-R assessment at least once a day over 5 days, and the best score obtained was used to determine the diagnosis. All diagnoses were confirmed with positron emission tomography. ${ }^{51}$

\section{Data Collection}

EEG signals were recorded from $12 \mathrm{Ag} / \mathrm{AgCl}$ ring electrodes at locations P3, P1, P2, P4, PO7, PO3, POz, PO4, PO8, O1, $\mathrm{Oz}$, and $\mathrm{O} 2$, referenced to $\mathrm{Pz}$, based on the international 10-20 electrode system. The ground electrode was placed on the right mastoid. All impedances were kept less than $5 \mathrm{kohm}$. Electrooculography was monitored using 4 electrodes: 2 on the left and on the right temples; the remaining 2 over and under the supra-orbital ridge. The amplifier used was a BrainVision V-Amp with a bandpass filter between 0.01 and $100 \mathrm{~Hz}$ and a sampling frequency of $250 \mathrm{~Hz}$. 


\section{Visual Stimulation}

The visual stimulation was delivered via a custom-made stimulation unit, which can be decomposed into a control unit and a stimulation panel. The panel, placed $30 \mathrm{~cm}$ away from the participant's head, was a $7 \times 7 \mathrm{~cm}^{2}$ "interlaced squares" made

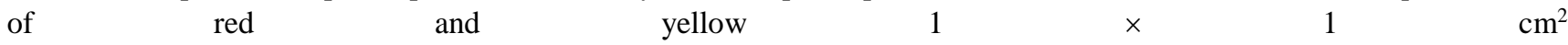

Table 1. Demographic and Clinical Data of Patients With Locked-in Syndrome (LIS).

\begin{tabular}{|c|c|c|c|c|c|c|}
\hline & Sex & Age (Years) & Etiology & Interval $^{\mathrm{a}}$ & MRI & Daily Communication Code \\
\hline$\overline{\text { LIS1 }}$ & Male & 47 & Brainstem stroke & 3 & $\begin{array}{l}\text { Cerebellar and pontomesencephalic } \\
\text { lesions }\end{array}$ & Verbalization via tracheostomy \\
\hline LIS2 & Male & 74 & Brainstem stroke & 3 & Pontomesencephalic and occipital lesions & $\begin{array}{l}\text { Yes (head movement) and no } \\
\text { (eyes closure) communication }\end{array}$ \\
\hline LIS3 & Female & 56 & Brainstem stroke & 15 & $\begin{array}{l}\text { Pontomesencephalic, middle cerebellar, } \\
\text { and occipital lesions }\end{array}$ & $\begin{array}{l}\text { Yes-no head movements } \\
\text { communication }\end{array}$ \\
\hline LIS4 & Male & 23 & Traumatic brainstem lesion & 7 & $\begin{array}{l}\text { Right cerebellar, right frontal and left } \\
\text { lenticular lesions. Diffuse axonal injury } \\
\text { in frontal and parietal lobes and the } \\
\text { lenticular capsula. Global cerebral } \\
\text { atrophy with quadriventriculaire } \\
\text { hydrocephalus }\end{array}$ & $\begin{array}{l}\text { Yes (looks right) and no (eyes } \\
\text { closure) communication }\end{array}$ \\
\hline LIS5 & Female & 30 & Brainstem stroke & 9 & Cerebellar and brainstem lesions & $\begin{array}{l}\text { Yes (eyes closure) and no (looks } \\
\text { up) communication }\end{array}$ \\
\hline LIS6 & Male & 64 & Brainstem stroke & 12 & $\begin{array}{l}\text { Pontine and diffuse periventricular } \\
\text { lesions }\end{array}$ & $\begin{array}{l}\text { Yes-no head movements } \\
\text { communication }\end{array}$ \\
\hline
\end{tabular}

${ }^{\mathrm{a}}$ Indicates the interval since insult (in years).

Table 2. Demographic and Clinical Data of VS/UWS Patients.

\begin{tabular}{|c|c|c|c|c|c|c|}
\hline & Sex & Age & Etiology & Interval $^{\mathrm{a}}$ & MRI & CRS-R \\
\hline VS1 & Female & 65 & Traumatic & 1 & $\begin{array}{l}\text { Global corticosubcortical atrophy with secondary } \\
\text { hydrocephalus. Cerebral microbleeds in right } \\
\text { frontal lobe. }\end{array}$ & 1(Au), 1(Vi), 2(M), 1(Ve), 0(C), 2(Ar) \\
\hline VS2 & Male & 62 & Anoxic & 2 & $\begin{array}{l}\text { Global corticosubcortical atrophy with secondary } \\
\text { hydrocephalus }\end{array}$ & 1(Au), 0(Vi), 1(M), 1(Ve), 0(C), 1(Ar) \\
\hline VS3 & Female & 38 & Anoxic & 4 & $\begin{array}{l}\text { Global corticosubcortical atrophy with secondary } \\
\text { hydrocephalus }\end{array}$ & 1(Au), 0(Vi), 1(M), 1(Ve), 0(C), 2(Ar) \\
\hline VS4 & Male & 31 & Anoxic & 3 & $\begin{array}{l}\text { Global corticosubcortical atrophy with secondary } \\
\text { hydrocephalus. Bilateral basal ganglia lesions }\end{array}$ & 1(Au), 0(Vi), 2(M), 1(Ve), 0(C), 1(Ar) \\
\hline VS5 & Female & 51 & $\begin{array}{r}\text { Subarachnoid } \\
\text { hemorrhage }\end{array}$ & 1 & $\begin{array}{l}\text { Global corticosubcortical atrophy with secondary } \\
\text { hydrocephalus. Brainstem posthemorrhage lesions }\end{array}$ & $1(\mathrm{Au}), 0(\mathrm{Vi}), 1(\mathrm{M}), 2(\mathrm{Ve}), 0(\mathrm{C}), 1(\mathrm{Ar})$ \\
\hline VS6 & Male & 51 & $\begin{array}{r}\text { Subarachnoid } \\
\text { hemorrhage }\end{array}$ & 1 & $\begin{array}{l}\text { Hippocampal, thalamic and corpus callosum } \\
\text { atrophy. }\end{array}$ & $1(\mathrm{Au}), 0(\mathrm{Vi}), 1(\mathrm{M}), 1 \mathrm{Ve}), 0(\mathrm{C}), 1(\mathrm{Ar})$ \\
\hline VS7 & Male & 31 & Traumatic & 5 & $\begin{array}{l}\text { Bihemispheric diffuse axonal injury. Brainstem, bifrontal } \\
\text { and parietal lesions. Global atrophy with secondary } \\
\text { hydrocephalus }\end{array}$ & 1(Au), 0(Vi), 1(M), 1(Ve), 0(C), 1(Ar) \\
\hline VS8 & Female & 52 & $\begin{array}{l}\text { Mixed (traumatic } \\
\text { and hypoxia) }\end{array}$ & 1 & $\begin{array}{l}\text { Global corticosubcortical atrophy with secondary } \\
\text { hydrocephalus. Bihemispheric diffuse axonal injury }\end{array}$ & 1(Au), 1(Vi), 2(M), 1(Ve), 0(C), 1(Ar) \\
\hline VS9 & Male & 28 & Traumatic & 7 & $\begin{array}{l}\text { Global corticosubcortical atrophy with secondary } \\
\text { hydrocephalus }\end{array}$ & 1(Au), 0(Vi), 1(M), 2(Ve), 0(C), 1(Ar) \\
\hline VS10 & Male & 21 & Traumatic & 1 & $\begin{array}{l}\text { Bihemispheric diffuse axonal injury. Brainstem, corpus } \\
\text { callosum, and bitemporal lesions }\end{array}$ & 1(Au), 1(Vi), 2(M), 1(Ve), 0(C), 1(Ar) \\
\hline
\end{tabular}

light-emitting diode (LED) squares with a white fixation cross in the middle (see Figure 1). The control unit was an electronic embedded system used to control red and yellow flickering frequencies, which can be varied independently between 1 and $99 \mathrm{~Hz}$ by a programmable integrated circuit microcontroller. During the experiment, the yellow and red squares were programmed to flicker at 10 and $14 \mathrm{~Hz}$, respectively.

\section{Paradigms}

A 5-minute recording at rest (resting-state activity, baseline) was collected at the beginning of the experiment. Then, each participant underwent a total of 6 runs, each lasting about 5 minutes, composed of ten 7-second active and ten 7-second 
passive trials (total of 60 active and 60 passive trials). Each 7-second trial was interspersed with an 8-second auditory instruction. During active trials, they were asked to look at the fixation cross while focusing their attention on one of the flashing colors (total of 30 times on red and 30 times on yellow, in a randomized order). During passive trials, participants were instructed to look at the fixation cross. Fixating may require a low level of attention. However, the level of attention should increase during active trials. Breaks between runs were offered and varied between participants depending on the level of fatigue.

Patients with LIS and VS/UWS are easily exhausted and can present eye-closure due to fatigue during the session. Patients' eyes were monitored during the recording session and, if prolonged eye-closure was observed, the run was interrupted and the arousal facilitation protocol, as established in the CRS-R administration guidelines, was performed before resuming the experimental procedure. We decided to reject data

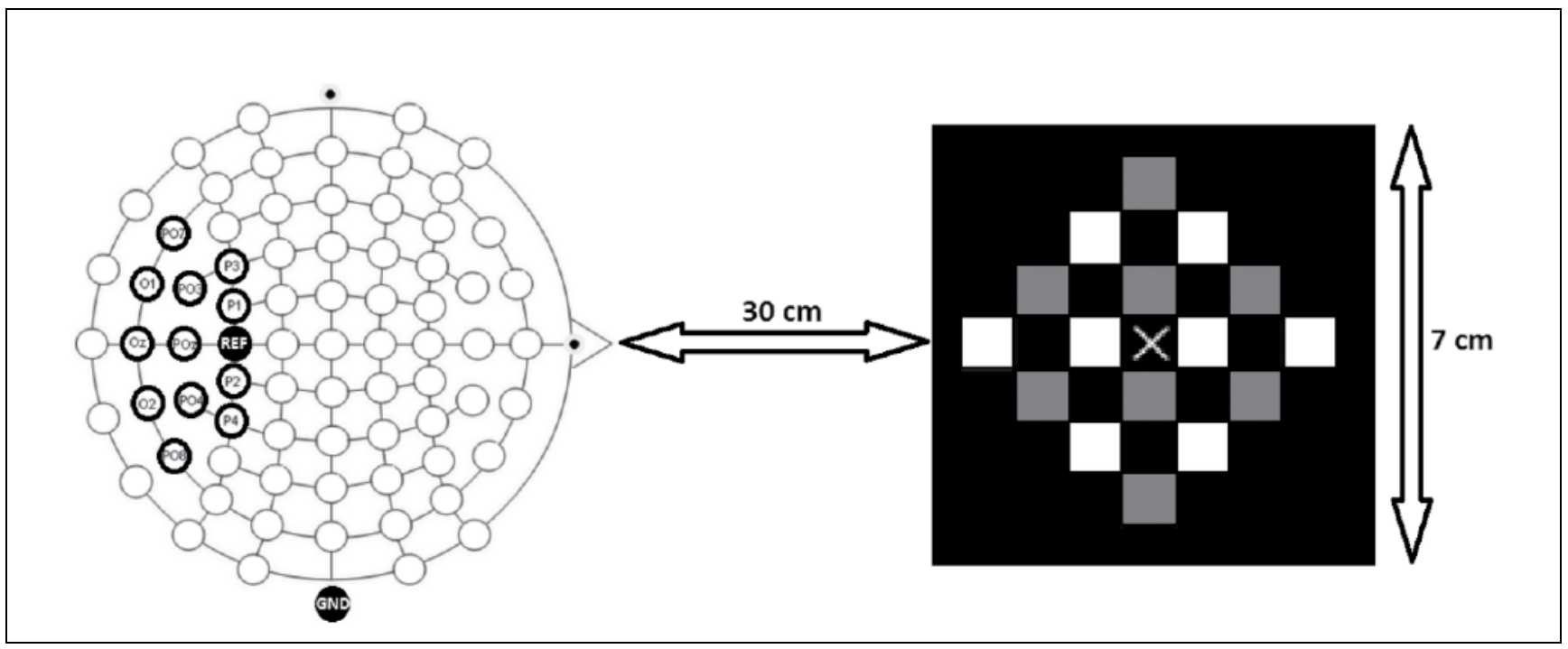

Figure 1. Experimental setup. On the left, the electrode locations. We recorded EEG from 12 posterior electrodes in the standard $10 / 20$ configuration. On the right, the electronic visual stimulation unit: yellow squares (in white) were flashed at a frequency of $10 \mathrm{~Hz}$. Red squares were flashed at $14 \mathrm{~Hz}$ (in gray). The subject was seated at $30 \mathrm{~cm}$ from the display and was instructed to passively look at the white cross (ie, passive trials) or to focus his attention on the yellow or red flashes (ie, active trials) while looking at the white cross. $\mathrm{X}$ is the fixation cross.

from these interrupted blocks from the analysis in order to avoid data with patients' unclear state of arousal, and repeated the rejected block as soon as the clinical expert confirmed sustained eye opening. Shortened eye-closure may induce change in the frequency spectrum over the occipital cortex, increasing the power in the alpha band. Increased alpha-band power may reduce the uniformity of the spectrum and decrease $\mathrm{SpE}$. In order to evaluate the effect of short eye-closures that could be observed in healthy volunteers and patients, the eyes-closed and eyes-open effect on the SpE in the passive condition was evaluated on 5 healthy volunteers.

\section{Data Analysis}

Preprocessing: EEG signals were preprocessed with a Butterworth fourth-order bandpass filter with a cutoff frequency of 0.5 to $60 \mathrm{~Hz}$, and an infinite impulse response notch filter ( $\mathrm{fc}=50 \mathrm{~Hz}, \mathrm{Q}=35$ ).

EEG Features: Spectral Entropy. Multitapers spectral analysis ${ }^{52,53}$ (7 tapers) was used to extract the power spectrum of each channel and on each 7-second active and 7-second passive trial, and to compute the $\mathrm{SpE}$ (frequency band: 0.5-32 $\mathrm{Hz}$ with a $0.5-\mathrm{Hz}$ step; 1 -second epochs) as defined by Viertio-Oja et $\mathrm{al}^{37}$ : 


$$
\operatorname{SpE}\left[f_{1}, f_{2}\right]=\frac{1}{\log \left(N\left[f_{1}, f_{2}\right]\right)} \cdot \sum_{f_{i}=f_{1}}^{f_{2}} P_{n}\left(f_{i}\right) \cdot \log \frac{1}{P_{n}\left(f_{i}\right)}
$$

where:

- $P_{n}\left(f_{i}\right)$ is the normalized power spectrum at frequency $f_{i}$. The normalization process divides each frequency power by the sum of all frequency powers.

- $N\left[f_{1} ; f_{2}\right]$ is equal to the total number of frequency components in the range $\left[f_{1} ; f_{2}\right]$.

Averaged SpE during each trial was extracted for each channel, resulting in 12 features per trial. To study the modulation of $\mathrm{SpE}$ between conditions, we also extract the entropy averaged over all electrodes on each second (1-second sliding window, no overlap) for each participant. We then computed the mean and standard deviation of the entropy in each condition (baseline, passive and active). Note that we computed the baseline entropy values on the whole 5-minute baseline recording at the beginning of each session, not on the rest periods between trials.

Mean SpE within the passive and active trials was computed on the 5 healthy participants participating in the eyes-closed versus eyes-open study.

EEG Features: Frequency Power Analyses. At each electrode location, we extracted mean EEG power spectral amplitude with multitapers spectral analysis (7 tapers) in delta (1-4 Hz), theta (4-8 Hz), alpha (8-12 Hz), and beta (12$30 \mathrm{~Hz}$ ) bands in nonoverlapping 1-second windows. Averaged EEG power during each trial was extracted for each channel, resulting in 12 features per band and per trial.

Classification and Statistical Analyses. Classification performances between active and passive trials were computed with a linear discriminant analysis (LDA), and assessed with a $10 \times 10$-fold cross-validation. A permutation test ${ }^{54,55}$ evaluated $^{-}$ the chance-level for each participant $(1000$ repetitions, LDA classification, $10 \times 10$-fold cross validation, $\mathrm{P}<.01)$. The significance of change between conditions (eyes-closed/eyes-open; baseline/passive/active; subject-level and group-level difference) was assessed with a non-parametric Wilcoxon signed-rank test (2-tailed, $\mathrm{P}<.01$ ). All analyses were done with custom-made code using MatLab. The BCI2000 software package ${ }^{56}$ and Fieldtrip Toolbox ${ }^{57}$ were used for data acquisition and presentation of the auditory instructions.

Effect of Trial Duration on Performance. We estimated the effect of the trial duration on the performance by analyzing reduced trials with a duration of 1 to 6 seconds by 1 -second increment. All trials started at the beginning of the original corresponding trial to replicate online condition, resulting in exactly the same number of trials. The classification procedure described above was replicated for the 6 concentration times. The results were compared with the results obtained with the full 7-second window with a Wilcoxon signed-rank test.

\section{Results}

\section{Spectral Entropy and Alpha Power Evolution Over Time}

Spectral entropy waveform shapes during active and passive trials in a representative participant from each group are illustrated in Figure 2 (full line). An increase of $\mathrm{SpE}$ at the beginning of the instruction of active trials could be observed in healthy volunteer and LIS groups, reaching a maximum during the active trial. At the end of the active trial, SpE decreased, reaching a minimum during the passive trial. A Wilcoxon signed-rank test indicated that $\mathrm{SpE}$ was higher in the active trials than in the passive trials for all healthy volunteers (at group level, active, $0.92 \pm 0.02$; passive, $0.86 \pm 0.04 ; Z=72.38, P<$ .01 ; at subject level, all $P$ values were <.01) and all LIS patients (at group level, active, $0.94 \pm 0.02$; passive, $0.90 \pm 0.03 ; Z$ $=32.78, P<.01$; at subject level, all $P$ values were <.01). None of the VS/UWS showed task-related variation of entropy between active condition $(0.95 \pm 0.02)$ and passive condition $(0.95 \pm 0.01)$, Wilcoxon signed-rank test, $Z=0.41, P=.68$ (see Table 3).

Averaged SpE during rest (baseline) could differentiate healthy volunteers ( $0.87 \pm 0.04$; range: $0.81-0.96$; see Table 3 ) from VS/UWS (0.94 \pm 0.02 ; range: 0.89-0.96) at group level (Wilcoxon signed-rank test, $Z=49.82, P<.01$ ). We did not run group comparison with LIS patients (range: 0.92-0.95) because of the small number of LIS patients. The ranges of values computed for each group covered each other, impairing the classification of individual participant into a given group.

Alpha power modulation over time could be observed between the attention task in all healthy volunteers (a high alpha power during passive trials followed by a low alpha power during active trials; Wilcoxon signed-rank test, at group level, $Z$ 
$=33.79, P<.01$; at subject level, all $P$ values were <.01) and 5 out of 6 patients with LIS (Wilcoxon signed-rank test, at group level, $Z=76.17, P<.01$; at subject level, all $P$ values were <.01, except for patient LIS2 with $P=.02, Z=2.39$; see Supplementary Figure $1, \quad$ available at http://eeg.sagepub.com/content/by/ supplemental-data). This alpha modulation was absent in all the VS/UWS patients (Wilcoxon signed-rank test, $P>.08, Z$ ranging from 0.05 to 2.01). For an illustrative example of the alpha power modulation between conditions, see Figure 2 (dashed line). Healthy volunteers illustrated higher power (Wilcoxon signed-rank test, $P<.01$; during active trials, $Z=$ 37.33; during passive trials, $Z=39.29$ ) in the alpha band (passive, $13.38 \pm 11.12 \mu \mathrm{V}^{2} / \mathrm{Hz}$; active, $1.94 \pm 1.76 \mu \mathrm{V}^{2} / \mathrm{Hz}$ ) than patients with VS/UWS (passive, $1.50 \pm 4.09 \mu \mathrm{V}^{2} / \mathrm{Hz}$; active, $0.36 \pm 1.98 \mu \mathrm{V}^{2} / \mathrm{Hz}$ ). During the baseline, alpha power was more variable than $\mathrm{SpE}$ (coefficient of variation, ie, std/mean, range; $\mathrm{SpE}=0.02-0.04$; alpha $=0.80-6.06$ ), Wilcoxon signedrank test, $Z=5.23, P<.01$.

Averaged spectral decomposition of 7-second windows during active and passive trials illustrates the importance of alpha band modulation between the active and passive conditions (Figure 3 and Supplementary Figures 2-4). Visually evoked potential peaks (see 10 and $14 \mathrm{~Hz}$, and the first harmonics, 20 and $28 \mathrm{~Hz}$, in Figure 3) were not discernable from background activity, illustrating their low influence on SpE modulation between active and passive conditions as compared with the alpha band. For a better view of the EEG power spectrum in the different conditions, please see Figure SM1 in the supplementary materials.

\section{Active Versus Passive Classification}

SpE could differentiate between active and passive conditions with a mean accuracy of $93 \% \pm 1 \%$ in the healthy volunteers (see Table 4). The patients with LIS achieved similar mean accuracy $(91 \% \pm 1 \%$; Wilcoxon signed-rank test, $Z=2.62, P=$ .287), while UWS/VS patients were at chance level (50\% $\pm 3 \%$; see Table 4). All 20 healthy volunteers, all the LIS patients, and none of the VS/UWS patients showed accuracy higher than chance-level illustrating a response-to-command (permutation test, 1000 permutations, $P<.01$; see Table 4, column 2).

For the healthy volunteers, classification of power in the EEG frequency bands at group level reached $62 \% \pm 2 \%$ (delta), $71 \% \pm 2 \%$ (theta), $77 \% \pm 2 \%$ (alpha), $75 \% \pm 2 \%$ (beta), and $76 \% \pm 2 \%$ (all bands together). For LIS patients, 

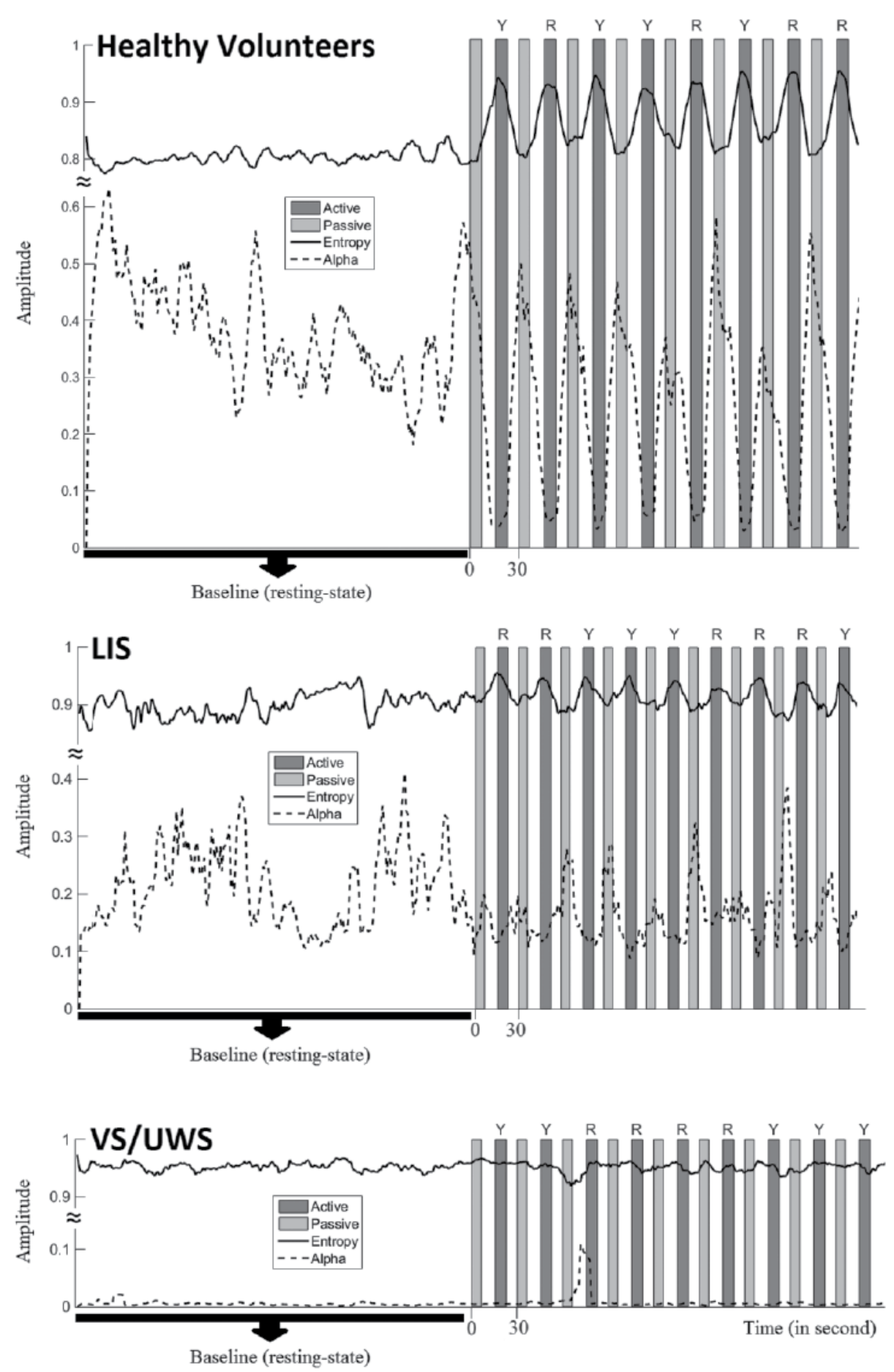

Figure 2. Time behavior of the $\mathrm{SpE}$ (full line) and alpha activity (dashed line), extracted with Multitapers Spectral analysis on nonoverlapping 1-second windows and averaged on all 12 posterior electrodes, computed for a representative healthy subject (first row), LIS patient (second row) and VS/UWS patient (third row). Dark gray and light gray blocks represent the active and passive trials, respectively. For active trials, the instructed color is mentioned on the top of the bloc ( $\mathrm{R}$ for red; $\mathrm{Y}$ for yellow). Intertrials white blocks represent the instruction period. Note the increase of $\mathrm{SpE}$ during the active trials (as compared with passive and baseline resting-state 
conditions) in healthy subjects and LIS patient, but not in VS/UWS patients. SpE, spectral entropy; LIS, locked-in syndrome; VS/UWS, vegetative state/unresponsive wakefulness syndrome.

Table 3. Mean \pm standard deviation of the spectral entropy in the different conditions (baseline, passive, and active). ${ }^{\mathrm{a}}$

\begin{tabular}{|c|c|c|c|c|c|}
\hline & Baseline & Passive & Active & $P$ & $Z$ \\
\hline \multicolumn{6}{|l|}{ Subject } \\
\hline HV1 & $0.88 \pm 0.03$ & $0.86 \pm 0.02$ & $0.9 \pm 0.03$ & $<.01$ & 14.41 \\
\hline HV2 & $0.89 \pm 0.05$ & $0.88 \pm 0.05$ & $0.94 \pm 0.02$ & $<.01$ & 16.61 \\
\hline HV3 & $0.90 \pm 0.03$ & $0.83 \pm 0.03$ & $0.93 \pm 0.02$ & $<.01$ & 19.90 \\
\hline HV4 & $0.87 \pm 0.03$ & $0.87 \pm 0.04$ & $0.92 \pm 0.02$ & $<.01$ & 16.37 \\
\hline HV5 & $0.86 \pm 0.04$ & $0.83 \pm 0.04$ & $0.93 \pm 0.02$ & $<.01$ & 19.87 \\
\hline HV6 & $0.88 \pm 0.04$ & $0.89 \pm 0.04$ & $0.94 \pm 0.02$ & $<.01$ & 16.61 \\
\hline HV7 & $0.82 \pm 0.03$ & $0.83 \pm 0.04$ & $0.90 \pm 0.02$ & $<.01$ & 17.22 \\
\hline HV8 & $0.84 \pm 0.03$ & $0.83 \pm 0.03$ & $0.92 \pm 0.02$ & $<.01$ & 19.72 \\
\hline HV9 & $0.85 \pm 0.04$ & $0.85 \pm 0.03$ & $0.90 \pm 0.02$ & $<.01$ & 18.35 \\
\hline HV10 & $0.88 \pm 0.03$ & $0.88 \pm 0.04$ & $0.92 \pm 0.02$ & $<.01$ & 13.43 \\
\hline HV11 & $0.81 \pm 0.03$ & $0.81 \pm 0.03$ & $0.88 \pm 0.02$ & $<.01$ & 17.94 \\
\hline HV12 & $0.89 \pm 0.03$ & $0.87 \pm 0.03$ & $0.91 \pm 0.02$ & $<.01$ & 17.51 \\
\hline HV13 & $0.81 \pm 0.05$ & $0.83 \pm 0.05$ & $0.92 \pm 0.02$ & $<.01$ & 17.56 \\
\hline HV14 & $0.89 \pm 0.03$ & $0.87 \pm 0.03$ & $0.91 \pm 0.02$ & $<.01$ & 16.68 \\
\hline HV15 & $0.86 \pm 0.03$ & $0.84 \pm 0.03$ & $0.91 \pm 0.02$ & $<.01$ & 19.76 \\
\hline HV16 & $0.96 \pm 0.01$ & $0.95 \pm 0.01$ & $0.96 \pm 0.01$ & $<.01$ & 14.64 \\
\hline HV17 & $0.83 \pm 0.04$ & $0.83 \pm 0.04$ & $0.93 \pm 0.02$ & $<.01$ & 19.52 \\
\hline HV 18 & $0.82 \pm 0.04$ & $0.88 \pm 0.05$ & $0.89 \pm 0.04$ & $<.01$ & 5.06 \\
\hline HV19 & $0.94 \pm 0.02$ & $0.94 \pm 0.02$ & $0.94 \pm 0.01$ & $<.01$ & 5.40 \\
\hline HV20 & $0.93 \pm 0.02$ & $0.91 \pm 0.03$ & $0.95 \pm 0.01$ & $<.01$ & 16.82 \\
\hline LIS1 & $0.93 \pm 0.02$ & $0.88 \pm 0.03$ & $0.94 \pm 0.02$ & $<.01$ & 13.83 \\
\hline LIS2 & $0.93 \pm 0.03$ & $0.93 \pm 0.03$ & $0.94 \pm 0.02$ & $<.01$ & 3.51 \\
\hline LIS3 & $0.94 \pm 0.02$ & $0.90 \pm 0.04$ & $0.95 \pm 0.01$ & $<.01$ & 13.07 \\
\hline LIS4 & $0.92 \pm 0.04$ & $0.86 \pm 0.03$ & $0.93 \pm 0.03$ & $<.01$ & 17.72 \\
\hline LIS5 & $0.95 \pm 0.01$ & $0.94 \pm 0.02$ & $0.95 \pm 0.01$ & $<.01$ & 8.83 \\
\hline LIS6 & $0.94 \pm 0.02$ & $0.91 \pm 0.03$ & $0.95 \pm 0.01$ & $<0.01$ & 17.00 \\
\hline UWS1 & $0.95 \pm 0.01$ & $0.95 \pm 0.01$ & $0.95 \pm 0.01$ & .901 & 0.06 \\
\hline UWS2 & $0.96 \pm 0.01$ & $0.95 \pm 0.01$ & $0.95 \pm 0.01$ & .983 & 0.02 \\
\hline UWS3 & $0.95 \pm 0.02$ & $0.96 \pm 0.02$ & $0.96 \pm 0.02$ & .297 & 1.04 \\
\hline UWS4 & $0.96 \pm 0.01$ & $0.96 \pm 0.01$ & $0.96 \pm 0.02$ & .884 & 0.15 \\
\hline UWS5 & $0.96 \pm 0.01$ & $0.96 \pm 0.01$ & $0.96 \pm 0.01$ & .264 & 1.11 \\
\hline UWS6 & $0.92 \pm 0.01$ & $0.91 \pm 0.01$ & $0.92 \pm 0.02$ & .661 & 1.41 \\
\hline UWS7 & $0.96 \pm 0.01$ & $0.96 \pm 0.01$ & $0.96 \pm 0.01$ & .135 & 1.49 \\
\hline UWS8 & $0.94 \pm 0.02$ & $0.94 \pm 0.02$ & $0.94 \pm 0.02$ & .536 & 0.62 \\
\hline UWS9 & $0.89 \pm 0.03$ & $0.92 \pm 0.02$ & $0.92 \pm 0.03$ & .478 & 0.71 \\
\hline UWS10 & $0.96 \pm 0.01$ & $0.96 \pm 0.01$ & $0.96 \pm 0.01$ & .476 & 0.71 \\
\hline \multicolumn{6}{|l|}{ Group } \\
\hline $\mathrm{HV}$ & $0.87 \pm 0.04$ & $0.86 \pm 0.04$ & $0.92 \pm 0.02$ & $<.01$ & 72.38 \\
\hline LIS & $0.93 \pm 0.02$ & $0.90 \pm 0.03$ & $0.94 \pm 0.02$ & $<.01$ & 32.78 \\
\hline UWS & $0.94 \pm 0.02$ & $0.95 \pm 0.01$ & $0.95 \pm 0.02$ & .68 & 0.41 \\
\hline
\end{tabular}

Abbreviations: LIS, locked-in syndrome; VS/UWS, vegetative state/unresponsive wakefulness syndrome; HV, healthy volunteer.

${ }^{a}$ The significance of change between the passive and active conditions was assessed with a nonparametric Wilcoxon signed rank-sum test with $P<.01$ ( $P$ and associated $Z$-test statistic are shown in the last 2 columns).

Table 4. Mean \pm standard deviation of classification accuracy (\%) obtained with spectral entropy (SpE), all EEG bands (R), alpha ( $\alpha$ ), beta $(\beta)$, theta $(\Theta)$, and delta $(\delta)$ analysis in Healthy Volunteers (HV), LIS Patients, and VS/UWS Patients.

\begin{tabular}{|c|c|c|c|c|c|c|c|}
\hline & $\mathrm{SpE}$ & $\mathrm{R}$ & $\delta$ & $\Theta$ & $\alpha$ & $\beta$ & \\
\hline \multicolumn{8}{|l|}{ Subject } \\
\hline HV1 & $91 \pm 1$ & $84 \pm 2$ & $68 \pm 2$ & $85 \pm 1$ & $80 \pm 2$ & $83 \pm 1$ & $\mathrm{SpE}$ \\
\hline HV2 & $97 \pm 0$ & $53 \pm 4$ & $55 \pm 3$ & $51 \pm 2$ & $70 \pm 3$ & $58 \pm 2$ & $\mathrm{SpE}$ \\
\hline HV3 & $99 \pm 0$ & $85 \pm 2$ & $63 \pm 3$ & $68 \pm 2$ & $86 \pm 1$ & $81 \pm 2$ & $\mathrm{SpE}$ \\
\hline HV4 & $98 \pm 0$ & $74 \pm 3$ & $65 \pm 2$ & $74 \pm 2$ & $75 \pm 1$ & $70 \pm 2$ & $\mathrm{SpE}$ \\
\hline HV5 & $99 \pm 0$ & $82 \pm 2$ & $68 \pm 2$ & $77 \pm 1$ & $81 \pm 2$ & $89 \pm 1$ & $\mathrm{SpE}$ \\
\hline HV6 & $87 \pm 1$ & $62 \pm 3$ & $55 \pm 3$ & $55 \pm 3$ & $63 \pm 2$ & $57 \pm 1$ & $\mathrm{SpE}$ \\
\hline HV7 & $96 \pm 1$ & $85 \pm 2$ & $57 \pm 4$ & $83 \pm 1$ & $90 \pm 1$ & $81 \pm 2$ & $\mathrm{SpE}$ \\
\hline HV8 & $98 \pm 0$ & $78 \pm 1$ & $67 \pm 2$ & $78 \pm 1$ & $80 \pm 1$ & $89 \pm 1$ & $\mathrm{SpE}$ \\
\hline HV9 & $94 \pm 1$ & $83 \pm 2$ & $72 \pm 1$ & $88 \pm 2$ & $74 \pm 2$ & $74 \pm 2$ & $\mathrm{SpE}$ \\
\hline HV10 & $86 \pm 1$ & $70 \pm 4$ & $60 \pm 2$ & $65 \pm 3$ & $68 \pm 2$ & $63 \pm 2$ & $\mathrm{SpE}$ \\
\hline HV11 & $99 \pm 0$ & $83 \pm 2$ & $61 \pm 2$ & $78 \pm 1$ & $82 \pm 1$ & $87 \pm 1$ & $\mathrm{SpE}$ \\
\hline HV12 & $99 \pm 0$ & $78 \pm 2$ & $56 \pm 2$ & $57 \pm 2$ & $80 \pm 1$ & $82 \pm 1$ & $\mathrm{SpE}$ \\
\hline HV13 & $92 \pm 1$ & $75 \pm 2$ & $66 \pm 2$ & $64 \pm 3$ & $71 \pm 2$ & $68 \pm 3$ & $\mathrm{SpE}$ \\
\hline HV14 & $97 \pm 0$ & $85 \pm 1$ & $62 \pm 3$ & $89 \pm 1$ & $87 \pm 1$ & $77 \pm 3$ & $\mathrm{SpE}$ \\
\hline HV15 & $99 \pm 0$ & $85 \pm 2$ & $61 \pm 2$ & $82 \pm 1$ & $89 \pm 0$ & $86 \pm 1$ & $\mathrm{SpE}$ \\
\hline
\end{tabular}




\begin{tabular}{|c|c|c|c|c|c|c|c|}
\hline HV16 & $86 \pm 1$ & $45 \pm 3$ & $51 \pm 2$ & $46 \pm 2$ & $53 \pm 3$ & $43 \pm 2$ & $\mathrm{SpE}$ \\
\hline HV17 & $99 \pm 0$ & $82 \pm 2$ & $59 \pm 2$ & $76 \pm 1$ & $82 \pm 1$ & $75 \pm 2$ & $\mathrm{SpE}$ \\
\hline HV18 & $69 \pm 1$ & $64 \pm 2$ & $55 \pm 3$ & $58 \pm 2$ & $56 \pm 2$ & $68 \pm 2$ & $\mathrm{SpE}, \beta$ \\
\hline HV19 & $84 \pm 2$ & $81 \pm 1$ & $67 \pm 2$ & $67 \pm 2$ & $70 \pm 1$ & $84 \pm 1$ & SpE \\
\hline HV20 & $99 \pm 0$ & $92 \pm 1$ & $69 \pm 2$ & $86 \pm 1$ & $94 \pm 1$ & $86 \pm 1$ & $\mathrm{SpE}$ \\
\hline LIS1 & $91 \pm 1$ & $77 \pm 3$ & $55 \pm 3$ & $73 \pm 2$ & $78 \pm 2$ & $75 \pm 2$ & $\mathrm{SpE}$ \\
\hline LIS2 & $91 \pm 2$ & $65 \pm 4$ & $73 \pm 2$ & $67 \pm 4$ & $68 \pm 2$ & $87 \pm 2$ & $\mathrm{SpE}$ \\
\hline LIS3 & $91 \pm 1$ & $68 \pm 6$ & $48 \pm 4$ & $77 \pm 2$ & $84 \pm 1$ & $72 \pm 3$ & $\mathrm{SpE}$ \\
\hline LIS4 & $100 \pm 0$ & $94 \pm 1$ & $66 \pm 2$ & $77 \pm 1$ & $95 \pm 1$ & $94 \pm 1$ & $\mathrm{SpE}$ \\
\hline LIS5 & $85 \pm 1$ & $89 \pm 2$ & $67 \pm 2$ & $83 \pm 1$ & $70 \pm 1$ & $70 \pm 2$ & $\mathrm{R}$ \\
\hline LIS6 & $89 \pm 1$ & $73 \pm 3$ & $68 \pm 2$ & $66 \pm 2$ & $79 \pm 2$ & $62 \pm 2$ & $\mathrm{SpE}$ \\
\hline UWS1 & $54 \pm 3$ & $49 \pm 4$ & $61 \pm 4$ & $56 \pm 2$ & $49 \pm 4$ & $52 \pm 3$ & - \\
\hline UWS2 & $48 \pm 3$ & $56 \pm 3$ & $46 \pm 4$ & $47 \pm 3$ & $63 \pm 3$ & $57 \pm 2$ & - \\
\hline UWS3 & $49 \pm 2$ & $49 \pm 3$ & $53 \pm 2$ & $51 \pm 2$ & $49 \pm 4$ & $42 \pm 5$ & - \\
\hline UWS4 & $49 \pm 4$ & $42 \pm 6$ & $41 \pm 4$ & $51 \pm 4$ & $47 \pm 5$ & $50 \pm 3$ & - \\
\hline UWS5 & $50 \pm 3$ & $48 \pm 3$ & $52 \pm 3$ & $52 \pm 3$ & $49 \pm 4$ & $44 \pm 4$ & - \\
\hline UWS6 & $44 \pm 2$ & $50 \pm 3$ & $46 \pm 4$ & $50 \pm 3$ & $54 \pm 3$ & $48 \pm 4$ & - \\
\hline UWS7 & $47 \pm 4$ & $58 \pm 2$ & $53 \pm 4$ & $60 \pm 3$ & $47 \pm 4$ & $69 \pm 3$ & $\beta$ \\
\hline UWS8 & $54 \pm 2$ & $54 \pm 3$ & $48 \pm 1$ & $50 \pm 3$ & $53 \pm 2$ & $50 \pm 3$ & - \\
\hline UWS9 & $47 \pm 3$ & $59 \pm 3$ & $56 \pm 2$ & $37 \pm 5$ & $42 \pm 3$ & $52 \pm 3$ & - \\
\hline UWS10 & $56 \pm 4$ & $50 \pm 4$ & $50 \pm 3$ & $55 \pm 3$ & $48 \pm 3$ & $53 \pm 4$ & - \\
\hline \multicolumn{8}{|l|}{ Group } \\
\hline HV & $93 \pm 1$ & $76 \pm 2$ & $62 \pm 2$ & $71 \pm 2$ & $77 \pm 2$ & $75 \pm 2$ & $\mathrm{SpE}$ \\
\hline LIS & $91 \pm 1$ & $78 \pm 2$ & $63 \pm 1$ & $74 \pm 1$ & $79 \pm 1$ & $77 \pm 1$ & $\mathrm{SpE}$ \\
\hline UWS & $50 \pm 3$ & $51 \pm 4$ & $52 \pm 3$ & $51 \pm 3$ & $50 \pm 4$ & $52 \pm 3$ & - \\
\hline
\end{tabular}

Abbreviations: LIS, locked-in syndrome; VS/UWS, vegetative state/unresponsive wakefulness syndrome.

${ }^{a}$ Accuracies above chance level (permutation test, $P<.01,1000$ permutations) are shown in bold. The significance of change between the different methods was assessed with a nonparametric Wilcoxon signed rank-sum test with $P<.01$.

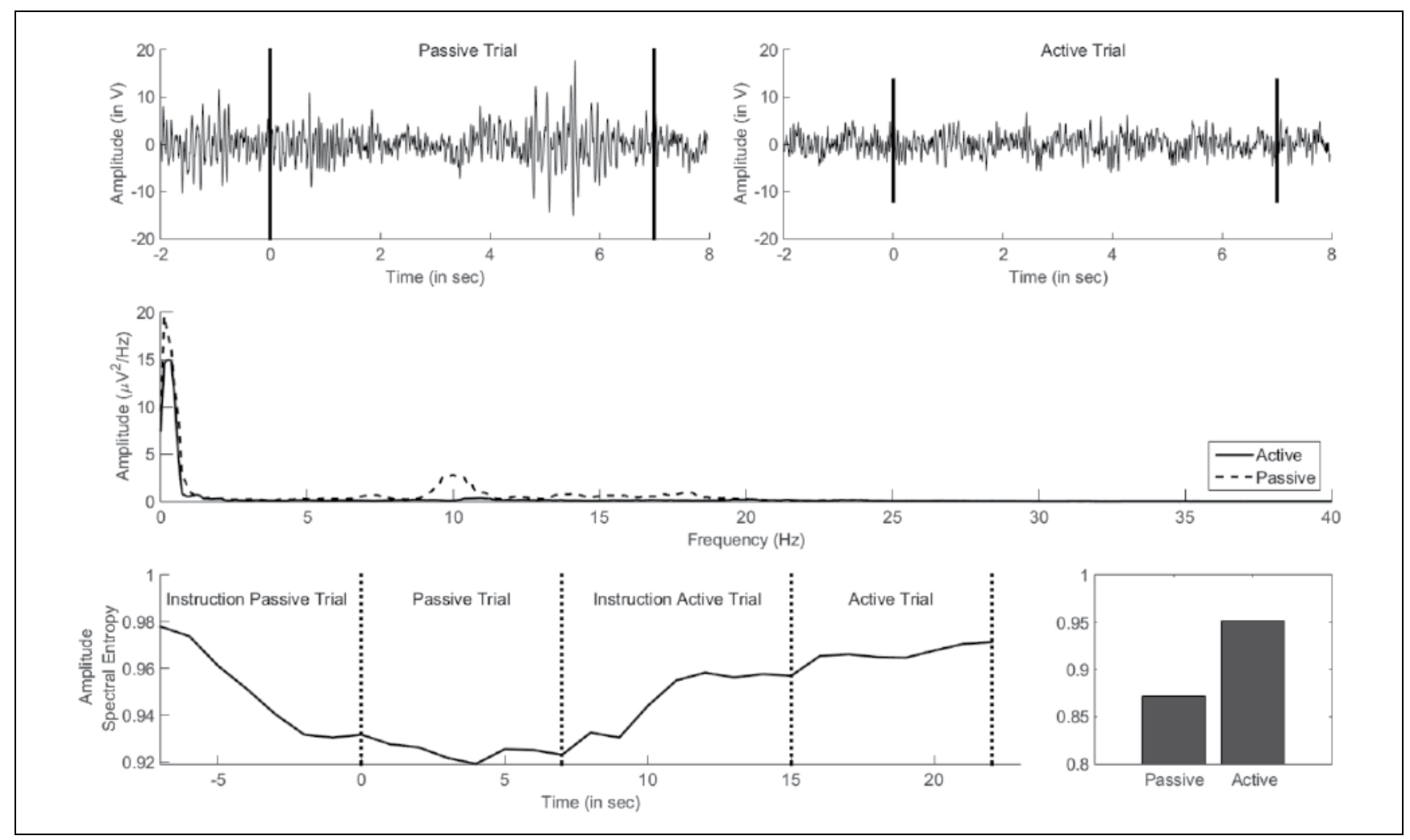

Figure 3. Representation of EEG time course, corresponding power spectrum and SpE for a patient with LIS. First row: raw EEG time course during a passive trial (left) and the corresponding active trial (right). Second row: power spectrum of 7-second active (full line) and 7-second passive (dotted line) trial presented in the first row. Third row: SpE time course during the trials presented in the first row and the intertrial instruction period (left). SpE for the passive (left) and active (right) trial presented in the first row. Note the increase of $\mathrm{SpE}$ from the passive trial to the active trial. Instruction period illustrate a transition state between "low-entropy" passive condition and "high-entropy" active condition. Healthy volunteer and VS/UWS patient's figure can be found in the supplementary materials (see Figure 
SM2-4, available at http://eeg.sagepub.com/content/by/supplemental-data). SpE, spectral entropy; LIS, locked-in syndrome; VS/UWS, vegetative state/unresponsive wakefulness syndrome.

Table 5. Comparison of method's performance on classifying task-related modification of attention (active vs passive) on healthy volunteers (white area) and patients with locked-in syndrome (gray area) ${ }^{\mathrm{a}}$ : Spectral entropy (SpE), All EEG bands (R), alpha $(\alpha)$, beta $(\beta)$, theta $(\Theta)$, and delta $(\delta)$.

\begin{tabular}{|c|c|c|c|c|c|c|}
\hline & SpE (6) & $\mathrm{R}(2)$ & $\delta(0)$ & $\Theta(1)$ & $\alpha(4)$ & $\beta(2)$ \\
\hline SpE (6) & & $\begin{array}{c}\mathrm{SpE} \\
(<.01)\end{array}$ & $\begin{array}{c}\mathrm{SpE} \\
(<.01)\end{array}$ & $\begin{array}{c}\mathrm{SpE} \\
(<.01)\end{array}$ & $\begin{array}{c}\mathrm{SpE} \\
(<.01)\end{array}$ & $\begin{array}{c}\mathrm{SpE} \\
(<.01)\end{array}$ \\
\hline $\mathrm{R}(3)$ & $\begin{array}{c}\mathrm{SpE} \\
(<.01)\end{array}$ & & $\underset{(<.01)}{\mathrm{R}}$ & $\underset{(<.01)}{\mathrm{R}}$ & $\overline{.332}$ &.$\overline{.146}$ \\
\hline$\delta(0)$ & $\begin{array}{c}\mathrm{SpE} \\
(<.01)\end{array}$ & $\begin{array}{c}\mathrm{R} \\
(<.01)\end{array}$ & & $\begin{array}{c}\Theta \\
(<.01)\end{array}$ & $\begin{array}{c}\alpha \\
(<.01)\end{array}$ & $\begin{array}{c}\beta \\
(<.01)\end{array}$ \\
\hline$\Theta(1)$ & $\begin{array}{c}\mathrm{SpE} \\
(<.01)\end{array}$ & $\begin{array}{c}\mathrm{R} \\
(<.01)\end{array}$ & $\begin{array}{c}\Theta \\
(<.01)\end{array}$ & & $\begin{array}{c}\alpha \\
(<.01)\end{array}$ & $\begin{array}{c}\beta \\
(<.01)\end{array}$ \\
\hline$\alpha(4)$ & $\begin{array}{c}\mathrm{SpE} \\
(<.01)\end{array}$ & $\overline{0.965}$ & $\begin{array}{c}\alpha \\
(<.01)\end{array}$ & $\begin{array}{c}\alpha \\
(<.01)\end{array}$ & & $\begin{array}{c}\alpha \\
(<.01)\end{array}$ \\
\hline$\beta(2)$ & $\begin{array}{c}\mathrm{SpE} \\
(<.01)\end{array}$ & $\begin{array}{c}\mathrm{R} \\
(<.01)\end{array}$ & $\begin{array}{c}\beta \\
(<.01)\end{array}$ & $\begin{array}{c}\beta \\
(<.01)\end{array}$ & $\begin{array}{c}\alpha \\
(<.01)\end{array}$ & \\
\hline
\end{tabular}

${ }^{a}$ Each row and column intersection illustrated the best of the 2 methods with the corresponding $P$ value (Wilcoxon signed rank-sum test, with $P<.01$ ). All comparison with $P>.01$ were considered not significant (-). For each method, we mention (on the first row for the LIS; on the first column for the HV) the number of outperformed methods.

the performances were $63 \% \pm 1 \%$ (delta), $74 \% \pm 1 \%$ (theta), $79 \% \pm 1 \%$ (alpha), $77 \% \pm 1 \%$ (beta), and $78 \% \pm 2 \%$ (all bands together). The VS/UWS group were at chance level. At the single-subject level, a response-to-command could be observed in 9/20 HV and 4/6 LIS (delta), 15/20 HV and 6/6 LIS (theta), 17/20 HV and 6/6 LIS (alpha), 17/20 HV and 5/6 LIS (beta), 15/20 HV and 6/6 LIS (all bands) (permutation test, 1000 permutations, $P<.01$ ). All but one VS/UWS patients were at chance-level (permutation test, 1000 permutations, all $P$ values were $>.05$, except for patient VS/UWS7 with $63 \%$ accuracy and $P<.01$; see Table 4, columns 3-7).

A Wilcoxon signed-rank test indicated that EEG-SpE illustrated higher performance than all the other methods in 19 out of $20 \mathrm{HV}$ and 5 out of $6 \mathrm{LIS}, Z$ range $=2.81$ to 2.88 , all $P$ values were $<.01$. HV18 showed performance similar to $\mathrm{SpE}$ with beta features (Wilcoxon signed-rank test, $Z=0.24, P=.81$ ). At the group level, EEG entropy classification outperformed all 6 other methods with an increase in accuracy ranging from $16 \%$ to $31 \%$ and from $12 \%$ to $28 \%$, respectively, in healthy volunteers and LIS patients (Wilcoxon signed-rank test, $P<.01$; see Table 5). As expected, alpha power features outperformed all the other bands, as well as the combination of bands.

\section{Effect of Trial Duration on Performance}

For healthy volunteers, similar performances were observed with trial of 5, 6, and 7 seconds (Wilcox on signed-rank test; $P$ $>$.01). For patients with LIS, no significant differences in the performance were observed for 4, 5, 6, and 7 seconds (Wilcoxon signed-rank test; $P>.01$ ). VS/UWS patients illustrated performance at chance level for all the different duration. Evolution of performance with the trial duration in healthy volunteers and patients with LIS are shown in Figure 4.

\section{Eyes-Closed Versus Eyes-Open}

Mean and standard deviation of the SpE averaged on all trials and healthy volunteers, for the eyes-closed versus eyes-open study, are shown in Figure 5. For both conditions, entropy increased from passive to active trials. There was no significant difference between eyes-open and eyes-closed conditions at single-subject level (Wilcoxon signed-rank test, $Z$ range: 0.13 $2.02, P>.080)$.

\section{Discussion}

The present study provides evidence that $\mathrm{SpE}$ can support the evaluation of response-to-command in an attention-based paradigm. All 20 healthy volunteers and the 6 LIS patients showed evidence of command-following while none of the tested VS/UWS patients did. While previous entropy studies in brain-injured population compute difference in the whole recording, the present study benefit of single-trial classification of active versus passive trials, opening the door to online $\mathrm{BCI}$ evaluation of response-to-command. Our measure combined with an attention paradigm enable to get information at 
single-subject level with higher accuracy than previous entropy studies in this population, only based on EEG resting-state activity.

Measures of EEG signal complexity, such as entropy, were initially developed for anesthesia monitoring. Gosseries et al ${ }^{44}$ showed a higher decrease of SpE during resting-state EEG recordings in patients with VS/UWS than minimally conscious state (MCS) in comparison with healthy volunteers. SpE could discriminate VS/UWS and MCS patients with a specificity and sensitivity of $89 \%$ in the acute setting. In chronic patients, however, SpE offered no reliable diagnostic information. Approximate entropy at rest also showed reduced complexity in patients with VS/UWS ${ }^{58}$ and prognostic capability. ${ }^{59}$ The bispectral

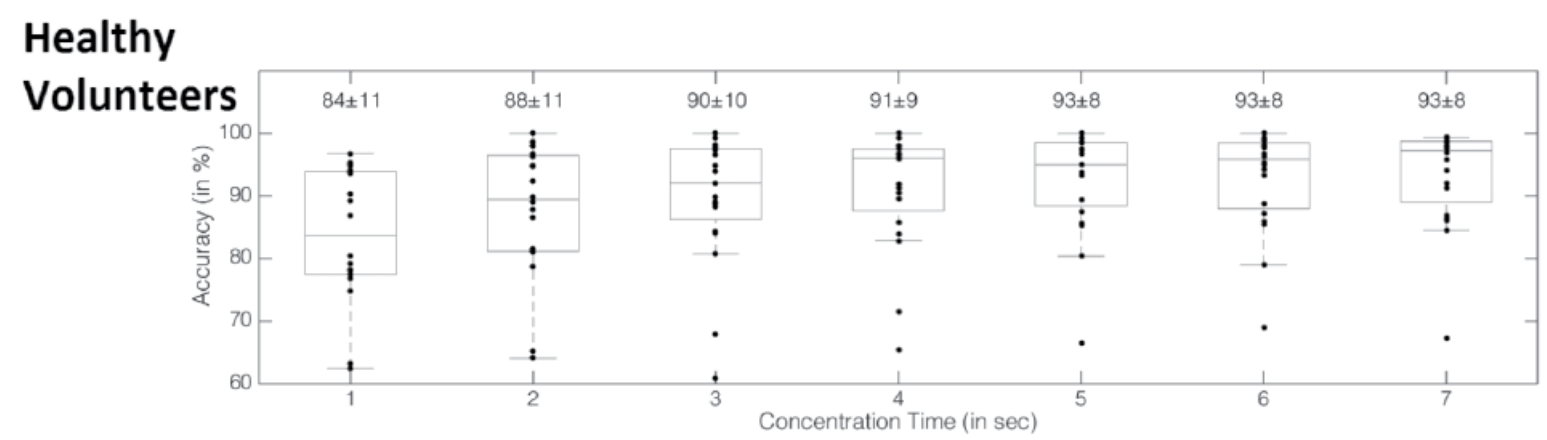

LIS

Patients

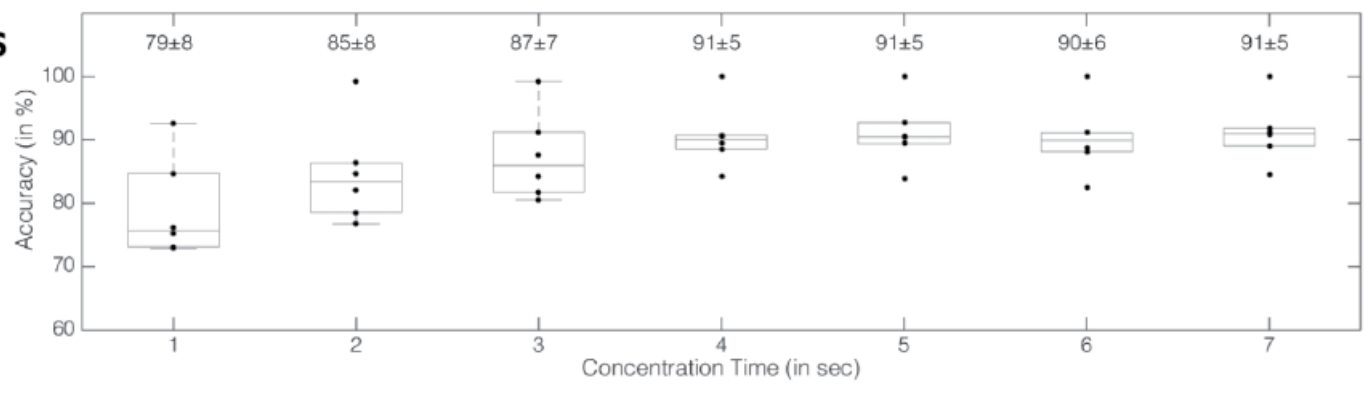

Figure 4. Evolution of performance with the trial duration in the healthy volunteers (upper) and patients with LIS (lower). Note the increasing performance with duration while reaching a plateau after 4 seconds (patients with LIS) and 5 seconds (healthy volunteers). 

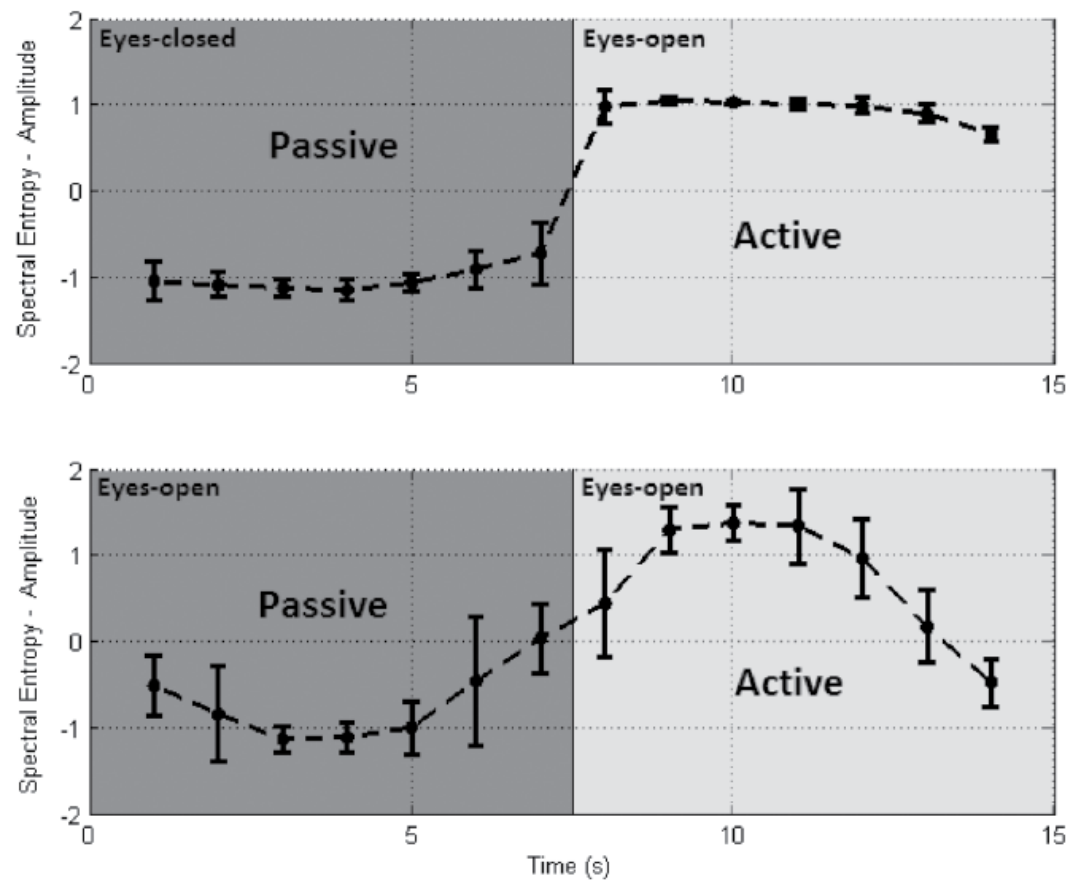

Figure 5. Mean and standard deviation of the spectral entropy $(\mathrm{SpE})$ for the passive $(n=60)$ and active $(n=60)$ trials averaged over all 12 posterior electrodes for 5 healthy subjects. The passive epoch is represented in dark gray and the active epoch in light gray. Note the increase in SpE during the active trials (eyes open) as compared with the passive trials acquired in both eyes-open (top) and eyes-closed (bottom) condition.

index, another measure of signal complexity, was also shown to correlate with scores of the Glasgow Coma Scale, ${ }^{60}$ and lower values at rest were observed in patients with VS/UWS than in patients with MCS.$^{61}$ However, these differences did not allow to distinguish patient's state at the individual level. ${ }^{62}$ Similarly, in the present article, averaged entropy measure at rest could not disentangle LIS from VS/UWS patients. This may reflect time-dependent cortical reorganization and plasticity already observed in brain-injured patients, ${ }^{63}$ inducing higher entropy in chronic VS/UWS patients than in acute patients. Alternatively, it could be related to contamination of the EEG signal by high-frequency muscle artifacts. ${ }^{42}$ Even if no obvious muscular artifacts contamination could be observed in our data, muscular artifacts may increase the entropy by increasing the frequency power at several or all frequencies. The short time window, 1 second, used to estimate the entropy, may also results in less accurate estimation of the frequency powers. The choice of the window length was based on the decision to track change in attention, not the general value of the resting entropy. Estimating the best length of different computation windows for the different frequencies, with increased size for the low frequencies and reduced size for the fast frequencies as in the original paradigm, ${ }^{44}$ would have requested a separate data set and will be part of a future study. Further patient studies are also needed to determine the robustness of an entropy-based approach to different levels of artifacts. We suppose that no change could be observed if the complexity measure is saturated by artifacts.

All LIS patients included in the present study have a means of communication, some even based on yes-no vocalizations or head movements. Furthermore, in this study, no LIS patient was in the acute state, which is the final target population of the present system. However, despite regaining residual control of movement over time, chronic LIS patient are the closest to the acute settings. The patients included in the present study have enough cognitive ability to communicate but 4 out of 6 were not able to respond-to-command with our covert SSVEP-BCI. ${ }^{11}$ In previous attempts to detect command-following in patients with LIS, an active auditory oddball task enabled detection of command-following in a complete LIS patient. ${ }^{6} \mathrm{~A}$ 4-choice auditory oddball enabled the detection in 1 LIS out of $2 .{ }^{24}$ A vibrotactile oddball was tested successfully on 6 patients with LIS. ${ }^{66}$ Functional MRI (fMRI) mental imagery was tested successfully on 5 patients with LIS in 2 separate studies. ${ }^{51,67}$ An EEG alternative of the mental imagery paradigm was tested with success in 1 patient with LIS. ${ }^{68}$ Finally, an hybrid P3-SSVEP paradigm detected command-following in 1 patient with LIS. ${ }^{69}$ Several studies also attempted to communicate with LIS patients using brain-computer interface and several training sessions. ${ }^{9,25,70-74}$ Not all patients were able to communicate. The results were influenced by the condition of the patient and the BCI paradigm. Altogether, these studies emphasize the potential of EEG and fMRI, when available, to detect command-following. 
We compared $\mathrm{SpE}$ and power spectrum variation in the alpha, beta, theta, and delta bands. Our results illustrated that $\mathrm{SpE}$ outperformed frequency band analyses at both group and single-subject levels. In particular, only SpE allows detecting a response-to-command in all healthy volunteers and LIS patients. This could be explained by the combined use of information inside all frequency bands with no prior assumptions. Indeed, although EEG alpha and beta bands have been widely used as a marker of attention in healthy volunteers, ${ }^{75}$ EEG recordings in patients with LIS have been reported to be normal in some patients but often show slowing of activity (limited or diffuse) and in some case abnormal patterns like alpha coma. ${ }^{62,76,77}$

$\mathrm{SpE}$ could be used in other paradigms using active tasks (eg, motor imagery ${ }^{68} \mathrm{P} 300^{23}$ ). Combining information from both approaches has the advantage of 2 evaluations of response-to-command with a single assessment. Our SpE index could also serve as a measure of attention permitting to better characterize BCI performance changes over time, especially relevant in the clinical context of severely brain damaged patients, known to frequently show fluctuations in arousal. ${ }^{5}$ Note that in the present study, electrodes in the posterior area were selected for data acquisition of the original SSVEP paradigm. These locations are probably suboptimal for the evaluation of SpE. Higher order association areas, such as the frontal areas, ${ }^{33}$ are known to be involved in attentional control and should be examined in future studies. The implementation of a real-time platform should also be considered to allow online clinical evaluation with EEG-based entropy measures directly at the patient's bedside. Changes in attention could also be used for single-switch online communication, similarly to Stoll et al $^{78}$ and Müller-Putz et al. $^{79}$

\section{Conclusion}

In this study, we examined the use of $\mathrm{SpE}$ to improve the detection of command-following in patients with severe motor disabilities. This measure $(a)$ needs no prior user training, $(b)$ requires a limited attention span for each trial (4-5 seconds), $(c)$ is based on a simple task, and $(d)$ is adapted for use at a patient's bedside. It may help reduce misdiagnoses between LIS and unconscious patients and could offer new prognostic information during the recovery following a coma.$^{80}$ Future studies could try the proposed methodology in patients with a minimally conscious state, showing nonreflexive behavior such as visual pursuit but no motor sign of response to command. ${ }^{81}$

\section{Authors' Note}

Authors Steven Laureys and Quentin Noirhomme contributed equally.

\section{Author Contributions}

DL contributed to conception and design; contributed to acquisition, analysis, and interpretation; drafted manuscript; critically revised manuscript; gave final approval; agrees to be accountable for all aspects of work ensuring integrity and accuracy. DH contributed to conception; contributed to acquisition; critically revised manuscript; gave final approval; agrees to be accountable for all aspects of work ensuring integrity and accuracy. CC contributed to conception; contributed to interpretation; critically revised manuscript; gave final approval; agrees to be accountable for all aspects of work ensuring integrity and accuracy. AS contributed to conception; contributed to interpretation; critically revised manuscript; gave final approval; agrees to be accountable for all aspects of work ensuring integrity and accuracy. SL contributed to conception; contributed to analysis and interpretation; critically revised manuscript; gave final approval; agrees to be accountable for all aspects of work ensuring integrity and accuracy. QN contributed to conception and design; contributed to analysis and interpretation; drafted manuscript; critically revised manuscript; gave final approval; agrees to be accountable for all aspects of work ensuring integrity and accuracy.

\section{Declaration of Conflicting Interests}

The author(s) declared no potential conflicts of interest with respect to the research, authorship, and/or publication of this article.

\section{Funding}

The authors received support by the National Funds for Scientific Research (FNRS), European ICT Programme Projects FP7-247919 DECODER and FP7- 602450 IMAGEMEND, James McDonnell Foundation, French Speaking Community Concerted Research Action, and University of Liege. The funders had no role in study design, data collection and analysis, decision to publish, or preparation of the manuscript.

\section{References}

1. American Congress of Rehabilitation Medicine. Recommendations for use of uniform nomenclature pertinent to patients with severe alterations of consciousness. Arch Phys Med Rehabil. 1995;76:205-209.

2. Bauer G, Gerstenbrand F, Rumpl E. Varieties of the locked-in syndrome. J Neurol. 1979;221:77-91.

3. Laureys S, Pellas F, Van Eeckhout P, et al. The locked-in syndrome: what is it like to be conscious but paralyzed and voiceless? Prog Brain Res. 2005;150:495-511.

4. The Multi-Society Task Force on PVS. Medical aspects of the persistent vegetative state. N Engl J Med. 1994;330:1499-1508. 
5. Majerus S, Gill-Thwaites H, Andrews K, Laureys S. Behavioral evaluation of consciousness in severe brain damage. Prog Brain Res. 2005;150:397-413.

6. Leon-Carrion J, van Eeckhout P, Dominguez-Morales R, Perez-Santamaria FJ. The locked-in syndrome: a syndrome looking for a therapy. Brain Inj. 2002;16:571-582.

7. Lukowicz M, Matuszak K, Talar A. A misdiagnosed patient: 16 years of locked-in syndrome, the influence of rehabilitation. Med Sci Monit. 2010;16:CS18-CS23.

8. Kübler A, Kotchoubey B, Kaiser J, Wolpaw JR, Birbaumer N. Brain-computer communication: unlocking the locked in. Psychol Bull. 2001;127:358-375.

9. Kübler A, Birbaumer N. Brain-computer interfaces and communication in paralysis: extinction of goal directed thinking in completely paralyzed patients? Clin Neurophysiol. 2008;119:2658-2666.

10. Noirhomme Q, Soddu A, Vanhaudenhuyse A, et al. Functional neuroimaging approaches to the changing borders of consciousness. J Psychophysiol. 2010;24:68-75.

11. Lesenfants D, Habbal D, Lugo Z, et al. An independent SSVEP-based brain-computer interface in locked-in syndrome. $J$ Neural Eng. 2014;11:035002.

12. Naci L, Monti MM, Cruse D, et al. Brain-computer interfaces for communication with nonresponsive patients. Ann Neurol. 2012;72:312-323.

13. Chatelle C, Chennu S, Noirhomme Q, Cruse D, Owen AM, Laureys S. Brain-computer interfacing in disorders of consciousness. Brain Inj. 2012;26:1510-1522.

14. Chaudhary U, Birbaumer N, Curado MR. Brain-machine interface (BMI) in paralysis. Ann Phys Rehabil Med. 2015;58:9-13.

15. Wolpaw JR, Birbaumer N, McFarland DJ, Pfurtscheller G, Vaughan TM. Brain-computer interfaces for communication and control. Clin Neurophysiol. 2002;113:767-791.

16. Guger C, Edlinger G, Harkam W, Niedermayer I, Pfurtscheller G. How many people are able to operate an EEG-based braincomputer interface (BCI)? IEEE Trans Neural Syst Rehabil Eng. 2003;11:145-147.

17. Guger C, Daban S, Sellers E, et al. How many people are able to control a P300-based-brain-computer interface (BCI)? Neurosci Lett. 2009;462:94-98.

18. Guger C, Allison BZ, Großwindhager B, et al. How many people could use an SSVEP BCI? Front Neurosci. 2012;6:169.

19. Blankertz B, Sannelli C, Halder S, et al. Neurophysiological predictor of SMR-based BCI performance. Neuroimage. 2010;51:13031309.

20. Allison B, Luth T, Valbuena D, Teymourian A, Volosyak I, Graser A. BCI demographics: how many (and what kinds of) people can use an SSVEP BCI? IEEE Trans Neural Syst Rehabil Eng. 2010;18:107-116.

21. Mak JN, Arbel Y, Minett JW, et al. Optimizing the P300-based brain-computer interface: current status, limitations and future directions. J Neural Eng. 2011;8:025003.

22. Piccione F, Giorgi F, Tonin P, et al. P300-based brain-computer interface: reliability and performance in healthy and paralysed participants. Clin Neurophysiol. 2006;117:531-537.

23. Kübler A, Furdea A, Halder S, Hammer EM, Nijboer F, Kotchoubey B. A brain-computer interface controlled auditory event-related potential (P300) spelling system for locked-in patients. Ann N Y Acad Sci. 2009;1157:90-100.

24. Lulé D, Noirhomme Q, Kleih S, et al. Probing command following in patients with disorders of consciousness using a braincomputer interface. Clin Neurophysiol. 2013;124:101-106.

25. Combaz A, Chatelle C, Robben A, et al. A comparison of two spelling brain-computer interfaces based on visual P3 and SSVEP in locked-in syndrome. PLoS One. 2013;8:e73691.

26. Davies DR, Parasuraman R. The Psychology of Vigilance. London, England: Academic Press; 1982.

27. Parasuraman R, Warm JS, See JE. Brain systems of vigilance in the attentive brain. In: Parasuraman R, ed. The Attentive Brain. Cambridge, MA: MIT Press; 1998:221-256.

28. Fruhstorfer H, Bergstrom R. Human vigilance and auditory evoked responses. Electroencephalogr Clin Neurophysiol. 1969;27:346355 .

29. Jung TP, Makeig S. Estimating level of alertness from EEG. Conf Proc IEEE Eng Med Biol Soc. 1994;2:1103-1104.

30. Jung TP, Makeig S, Stensmo M, Sejnowski TJ. Estimating alertness from the EEG power spectrum. IEEE Trans Biomed Eng. 1997;44:60-69.

31. Loewy DH, Campbell KB, de Lugt DR, Elton M, Kok A. The mismatch negativity during natural sleep: intensity deviants. Clin Neurophysiol. 2000;111:863-872.

32. Belyavin A, Wright N. Changes in electrical activity of the brain with vigilance. Electroencephalogr Clin Neurophysiol. 1987;66:137-144.

33. Shannon CE. A mathematical theory of communication. Bell Syst Tech J. 1948;27:623-656.

34. Pincus S. Approximate entropy as a measure of system complexity. Proc Natl Acad Sci U S A. 2001;88:2297-2301.

35. Jordan D, Stockmanns G, Kochs EF, Pilge S, Schneider G. Electroencephalographic order pattern analysis for the separation of consciousness and unconsciousness: an analysis of approximate entropy, permutation entropy, recurrence rate, and phase coupling of order recurrence plots. Anesthesiology. 2008;109:1014-1022.

36. Quiroga RQ, Rosso OA, Başar E, Schürmann M. Wavelet entropy in event-related potentials: a new method shows ordering of EEG oscillations. Biol Cybern. 2001;84:291-299.

37. Viertiö-Oja H, Maja V, Särkelä M, et al. Description of the Entropy ${ }^{\mathrm{TM}}$ algorithm as applied in the Datex-Ohmeda S/5TM entropy module. Acta Anaesthesiol Scand. 2004;48:154-161.

38. Burioka N, Miyata M, Cornélissen G, et al. Approximate entropy in the electroencephalogram during wake and sleep. Clin EEG Neurosci. 2005;36:21-24. 
39. Lee GM, Fattinger S, Mouthon AL, Noirhomme Q, Huber R. Electroencephalogram approximate entropy influenced by both age and sleep. Front Neuroinform. 2013;7:33.

40. Bruhn J, Ropcke H, Hoeft A. Approximate entropy as an electroencephalographic measure of anesthetic drug effect during desflurane anesthesia. Anesthesiology. 2000;92:715-726.

41. Bruhn J, Röpcke H, Rehberg B, Bouillon T, Hoeft A. Electroencephalogram approximate entropy correctly classifies the occurrence of burst suppression pattern as increasing anesthetic drug effect. Anesthesiology. 2000;93:981-985.

42. Bruhn J, Bouillon TW, Radulescu L, Hoeft A, Bertaccini E, Shafer SL. Correlation of approximate entropy, bispectral index, and spectral edge frequency 95 (SEF95) with clinical signs of "anesthetic depth" during coadministration of propofol and remifentanil. Anesthesiology. 2003;98:621-627.

43. Srinivasan V, Eswaran C, Sriraam N. Approximate entropy-based epileptic EEG detection using artificial neural networks. IEEE Trans Inf Technol Biomed. 2007;11:288-295.

44. Gosseries O, Schnakers C, Ledoux D, et al. Automated EEG entropy measurements in coma, vegetative state/unresponsive wakefulness syndrome and minimally conscious state. Funct Neurol. 2011;36:25-30.

45. Höller Y, Bergmann J, Thomschewski A, et al. Comparison of EEG-features and classification methods for motor imagery in patients with disorders of consciousness. PLoS One. 2013;8:e80479.

46. Höller Y, Thomschewski A, Bergmann J, et al. Connectivity biomarkers can differentiate patients with different levels of consciousness. Clin Neurophysiol. 2014;125:1545-1555.

47. King JR, Sitt JD, Faugeras F, et al. Information sharing in the brain indexes consciousness in non-communicative patients. Curr Biol. 2013;23:1914-1919.

48. Sitt JD, King JR, El Karoui I, et al. Large scale screening of neural signatures of consciousness in patients in a vegetative or minimally conscious state. Brain. 2014;137(pt 8):2258-2270.

49. Giacino JT, Kalmar K, Whyte J. The JFK Coma Recovery Scale-Revised: measurement characteristics and diagnostic utility. Arch Phys Med Rehabil. 2004;85:2020-2029.

50. Seel RT, Sherer M, Whyte J, et al. Assessment scales for disorders of consciousness: evidence-based recommendations for clinical practice and research. Arch Phys Med Rehabil. 2010;91:1795-1813.

51. Stender J, Gosseries O, Bruno MA, et al. Diagnostic precision of PET imaging and functional MRI in disorders of consciousness: a clinical validation study. Lancet. 2014;384:514-522.

52. Thomson DJ. Spectrum estimation and harmonic analysis. Proc IEEE. 1982;70:1055-1096.

53. Hoogenboom N, Schoffelen JM, Oostenveld R, Parkes LM, Fries P. Localizing human visual gamma-band activity in frequency, time and space. Neuroimage. 2006;29:764-773.

54. Nichols TE, Holmes AP. Non-parametric permutation tests for functional neuroimaging: a primer with examples. Hum Brain Mapp. 2002;15:1-25.

55. Noirhomme Q, Lesenfants D, Gomez F, et al. Biased binomial assessment of cross-validated estimation of classification accuracies illustrated in diagnosis predictions. Neuroimage Clin. 2014;4:687-694.

56. Schalk G, McFarland DJ, Hinterberger T, Birbaumer N, Wolpaw JR. BCI2000: a general-purpose brain-computer interface (BCI) system. IEEE Trans Biomed Eng. 2004;51:1034-1043.

57. Oostenveld R, Fries P, Maris E, Schoffelen JM. Fieldtrip: open source software for advanced analysis of MEG, EEG, and invasive electrophysiological data. Comput Intell Neurosci. 2011;2011:156869.

58. Sarà M, Pistoia F. Complexity loss in physiological time series of patients in a vegetative state. Nonlinear Dynamics Psychol Life Sci. 2010;14:1-13.

59. Wu DY, Cai G, Yuan Y, et al. Application of nonlinear dynamics analysis in assessing unconsciousness: a preliminary study. Clin Neurophysiol. 2010;122:490-498.

60. Gill M, Green SM, Krauss B. Can the bispectral index monitor quantify altered level of consciousness in emergency department patients? Acad Emerg Med. 2003;10:175-179.

61. Schnakers C, Ledoux D, Majerus S, et al. Diagnostic and prognostic use of bispectral index in coma, vegetative state and related disorders. Brain Inj. 2008;22:926-931.

62. Lehembre R, Gosseries O, Lugo Z, et al. Electrophysiological investigations of brain function in coma, vegetative and minimally conscious patients. Arch Ital Biol. 2012;150:122-139.

63. Navarro X. Chapter 27: neural plasticity after nerve injury and regeneration. Int Rev Neurobiol. 2009;87:83-505.

64. Lugo ZR, Rodriguez J, Lechner A, et al. A vibrotactile p300-based brain-computer interface for consciousness detection and communication. Clin EEG Neurosci. 2014;45:14-21.

65. Bardin JC, Fins JJ, Katz DI, et al. Dissociations between behavioural and functional magnetic resonance imaging-based evaluations of cognitive function after brain injury. Brain. 2011;134(pt 3):769-782.

66. Goldfine AM, Victor JD, Conte MM, Bardin JC, Schiff ND. Determination of awareness in patients with severe brain injury using EEG power spectral analysis. Clin Neurophysiol. 2011;122:2157-2168.

67. Pan J, Xie Q, He Y, et al. Detecting awareness in patients with disorders of consciousness using a hybrid brain-computer interface. J Neural Eng. 2014;11:056007.

68. Birbaumer N, Ghanayim N, Hinterberger T, et al. A spelling device for the paralysed. Nature. 1999;398:297-298.

69. Neuper C, Müller GR, Kübler A, Birbaumer N, Pfurtscheller G. Clinical application of an EEG-based brain-computer interface: a case study in a patient with severe motor impairment. Clin Neurophysiol. 2003;114:399-409.

70. Sellers EW, Vaughan TM, Wolpaw JR. A brain-computer interface for long-term independent home use. Amyotroph Lateral Scler. 2010;11:44955.

71. Townsend G, LaPallo BK, Boulay CB, et al. A novel P300-based brain-computer interface stimulus presentation paradigm: moving beyond rows and columns. Clin Neurophysiol. 2010;121:1109-1120. 
72. Höhne J, Holz E, Staiger-Sälzer P, Müller KR, Kübler A, Tangermann M. Motor imagery for severely motor-impaired patients: evidence for brain-computer interfacing as superior control solution. PLoS One. 2014;9:e104854. 
73. Melinscak F, Montesano L, Minguez J. Discriminating between attention and mind wandering during movement Using EEG. Proc 6th BCI Int Conf. 2014;2014:314-317.

74. Gosseries O, Bruno MA, Vanhaudenhuyse A, Laureys S, Schnakers. Consciousness in the locked-in syndrome. In: Laureys S, Tononi G, eds. The Neurology of Consciousness: Cognitive Neuroscience and Neuropathology. London, England: Academic Press/Elsevier; 2009:191-203.

75. Nam C, Woo J, Bahn S. Severe motor disability affects functional cortical integration in the context of brain-computer interface (BCI) use. Ergonomics. 2012;55:581-591.

76. Stoll J, Chatelle C, Carter O, Koch C, Laureys S, Einhäuser W. Pupil responses allow communication in locked-in syndrome patients. Curr Biol. 2013;23:647-648.

77. Müller-Putz GR, Pokorny C, Klobassa D, Horki P. A single switch BCI based on passive and imagined movements: toward restoring communication in minimally conscious patients. Int J Neural Syst. 2013;23:1250037.

78. Laureys S, Schiff N. Coma and consciousness: paradigms (re)framed by neuroimaging. Neuroimage. 2012;61:478-491.

79. Bruno MA, Majerus S, Boly M, et al. Functional neuroanatomy underlying the clinical subcategorization of minimally conscious state patients. J Neurol. 2011;259:1087-1098. 